\title{
La contabilidad como tecnología blanda: una visión desde los imaginarios sociales*
}

\author{
Accounting as a Soft Technology: a Vision from Social Imaginaries \\ A contabilidade como tecnologia suave: uma visão desde os imaginários sociais
}

Gabriel Jacob Velandia-Pacheco ${ }^{\text {a }}$

Universidad Nacional de Rosario, Argentina

gvelandi1@cuc.edu.co

ORCID: http://orcid.org/0000-0002-0185-2390

Fecha de recepción: 14 Marzo 2016

Alfredo Rafael Anguila-Carrillo

Fecha de aprobación: 10 Febrero 2017

Corporación Universitaria Empresarial de Salamanca,

Colombia

ORCID: http://orcid.org/0000-0001-5955-8437

Wendell Graham Archibold-Barrios

Universidad del Atlántico, Colombia

Universidad Nacional de Rosario, Argentina

ORCID: http://orcid.org/0000-0002-0899-5407

\section{Resumen:}

Este artículo tiene como objetivo la construcción de un concepto de contabilidad desde el enfoque de imaginarios sociales, teniendo en cuenta sus fines, carácter científico y la sociedad. Esta ha entendido la contabilidad como sistema de información incubado en rutinas y monotonías rigurosamente diseñadas y conservadas que satisfacen lo legal-instrumental, e influyen en el imaginario social que la entiende como oficio, y permean el actuar universitario influenciado por la visión empresarial de la educación. Surge de la reflexión de resultados de una investigación de revisión bibliográfica, de alcance analítico-interpretativo, en la que se estudian paralelamente documentos de la sociología y de investigación en contabilidad y se buscan puntos de convergencia, de los que puedan surgir interpretaciones que permitan la construcción de un concepto de contabilidad, desde lo epistemológico, taxonómico, teleológico y ontológico. Los resultados permiten negar el estatus de ciencia de la contabilidad y entenderla como tecnología blanda y como tal, una disciplina que genera su propio objeto de estudio, que funciona como medio en la construcción del imaginario colectivo con el que se construye sociedad. Esto repercute en la necesidad de definir qué aspectos de la sociedad son construidos a partir de la información contable y el papel científico del contador público en este contexto.

Código JEL: M41

Palabras clave: Contabilidad, ciencia, tecnología, imaginario social, sociedad.

\section{Abstract:}

The aim of this article is to build a concept of accounting from the perspective of social imaginaries, taking into account its aims, scientific character, and society. Society has understood accounting as an information system developed in routine and monotony, rigorously designed and preserved as to satisfy its legal-instrumental purposes, and that influence the social imaginary of its understanding as a career as well as permeate the university actions, influenced by a business-like vision of education . This research arises from the reflection of the results of a literature review of analytical-interpretative scope, in which documents of sociology and research in accounting are studied in parallel and points of convergence are sought, from which interpretations that allow the construction of an accounting concept, based on epistemological, taxonomic, teleological, and ontological concepts. The results allow us to deny the status of accounting as a science and understand it as a soft technology; as such, it is a discipline that generates its own object of study that works as a means in the construction of the collective imaginary with which society is built. This has an impact on the need to define the aspects of society are constructed based on accounting information and the scientific role of the public accountant in this context.

Keywords: Accounting, science, technology, social imaginary, society.

Notas de autor 


\section{Resumo:}

Este artigo objetiva construir um conceito de contabilidade desde o enfoque de imaginários sociais, tendo em consideração seus fins, caráter científico e sociedade. Esta compreende a contabilidade como sistema de informação incutido em rotinas e monotonias rigorosamente concebidas e conservadas a satisfazer o legal-instrumental, e influentes no imaginário social que entende ela como ofício, e permeiam o agir universitário influenciado pela visão empresarial do ensino. Decorre da reflexão de resultados de uma pesquisa de revisão bibliográfica, de escopo analítico-interpretativo, na que, paralelamente, documentos da sociologia e da pesquisa na contabilidade são estudados e pontos de convergência procurados, dos que podem até surgir interpretações que permitem a construção de um conceito de contabilidade, desde o epistemológico, taxonômico, teleológico e ontológico. Os resultados dão para negar o status de ciência da contabilidade e compreendê-la como tecnologia suave e, portanto, uma disciplina que gera seu próprio objeto de estudo, que funciona como meio na construção do imaginário coletivo com que a sociedade é construída. Isso impacta na necessidade de definir quais aspetos da soiedade são construídos a partir da informação contábil e o papel científico do contador público nesse contexto.

Palavras-chave: Contabilidade, ciência, tecnologia, imaginário social, sociedade.

\section{Introducción}

Desde una perspectiva ortodoxa, el desarrollo de la profesión contable ha sido históricamente descrito a partir del quehacer empírico, un rasgo relevante de las artes y los oficios, más que de las disciplinas científi cas. Los trabajos de investigación en esta área del conocimiento son relativamente recientes y los correspondientes a la primera década del siglo XX no muestran el interés de sus autores por definir o construir un concepto de contabilidad, las preocupaciones giraban en torno a cuestiones de carácter técnico-práctico (Mejía-Soto, Mora-Roa, \& Montes-Salazara, 2013).

Desde esta óptica empírica, se consolida un robusto sistema de información, que propende por identifi car y valorar el estado de circulación de la riqueza controlada por las organizaciones (Mejía-Soto, MontesSalazar \& Mora-Roa, 2013), medir o determinar la magnitud de esa circulación, clasificarla según su naturaleza en las cuentas (activos, pasivos, patrimonio, ingresos, costos o gastos) y realizar registros de estas transacciones. Además de lo anterior y basada en la información lograda en lo que se llama su "etapa inicial" o "de registro", la contabilidad permite interpretar aquello que significa esa circulación, analizarla, evaluar sus efectos e informar.

$\mathrm{Al}$ entender la contabilidad como un proceso del cual se exige información clara, completa y fidedigna, gran parte de los profesionales de esta disciplina ha centrado sus esfuerzos en la elaboración minuciosa de los registros contables y estados financieros, para cumplir completamente con la etapa inicial de la contabilidad, y pasar luego a la etapa de informar. Esta visión de la contabilidad otorga menos preponderancia a la interpretación y al análisis de la información, funciones que en la práctica, son ejercidas generalmente por otro tipo de profesionales.

Esta visión miope de las disciplinas contables, recibida como herencia de su pasado pragmático, está tan impregnada en el imaginario social, que las mismas universidades han reproducido este modelo en los estudiantes, lo cual contribuye a la formación de un contador público de escasa imaginación, con personalidad más bien cuadriculada, muy formal y de apariencia grisácea. Se enseñan los procedimientos contables con énfasis en la rigurosidad de los procesos y en la exigibilidad y aparente perfección que expresa las sumas iguales en las columnas débito y crédito.

Carlos Mario Ospina-Zapata, Mauricio Gómez-Villegas y William Rojas-Rojas (2014) plantean que, en la formación de contadores, las universidades participan en la constitución de una subjetividad caracterizada por el predominio de la formación hecha por el sujeto competente en ciertos ejercicios del actuar profesional, con gran debilidad en las comprensiones contextuales y en la capacidad de problematizarse en la complejidad del mundo de la vida. Por otra parte, Guillermo León Martínez-Pino (2007) plantea que se debe adoptar una postura de mayor rigurosidad interpretativa que permita superar las precariedades de una disciplina enfocada en un positivismo económico normativo y tributario, que ha subsumido a la profesión en una inercia interpretativa. 
En este sentido, puede decirse que el imaginario social compartido afecta directamente la forma en la que se enseña contabilidad y, por tanto, en la formación del contador público. Los estudiantes y docentes concentrados en el "hacer registros para informar" consideran innecesarias las reflexiones en torno al significado de: contabilidad, recursos, riqueza, propiedad; y derivado de esto: sociedad, política y decisiones públicas, entre otras. De tal forma, que muchos estudiantes ${ }^{1}$ al ser cuestionados sobre qué es la contabilidad y al pedirles definir el objeto de estudio de su profesión, no encuentran camino por dónde representar teóricamente todo el hacer empírico para el que han sido preparados. No encuentran relación alguna entre contabilidad, sociedad y política y mucho menos comprenden su papel como profesionales en la sociedad. En coherencia con Olver Quijano-Valencia, Édgar Gracia-López, Guillermo León Martínez-Pino, Efrén Danilo Ariza-Buenaventura y William Rojas-Rojas (2002), no hay coincidencia en el valor de la ciencia en el ambiente universitario de la contabilidad entre directivos, docentes y estudiantes.

Este marcado desconocimiento de lo social, manifestado desde la misma formación, incita a indagar por los principales aspectos que relacionan la contabilidad con la sociedad, a la vez que legitima un vacío en el conocimiento, el cual hace un llamado a la curiosidad y el inconformismo de los investigadores y docentes que propenden por enseñar contabilidad desde un enfoque más emancipador. Esto es, en coherencia con Patti Lather (1992), enmarcado en un contenido crítico, neomarxista, feminista, específico a la raza, participativo y freiriano. En este punto, debe reconocerse el trabajo de los académicos contables, quienes han logrado significativos avances en la educación contable en Colombia, incluyendo los aspectos antes relacionados en los procesos de formación.

A pesar del invaluable trabajo de la comunidad académica contable que sigue la corriente crítica y de sus importantes avances en los procesos educativos, aún puede evidenciarse la ausencia de asignaturas que inviten a reflexiones críticas en muchas instituciones de educación superior en el país, lo cual evidencia que en muchos segmentos de la sociedad prevalece la idea de contabilidad como disciplina del hacer y la heterogeneidad en los contenidos de asignaturas tales como teoría contable o investigación contable ${ }^{2}$.

Lo anterior ha motivado a tener en cuenta la sociedad en la que está inmersa la contabilidad y trabajar en la construcción de un concepto de la misma, considerando aspectos relevantes de las interrelaciones generadas en la sociedad. Teniendo en cuenta siempre que la contabilidad es social por naturaleza, por tanto, vista de manera transversal.

Esta discusión lleva a definir inicialmente, desde un enfoque epistemológico, cómo se enmarca la contabilidad en los conceptos de ciencia, disciplina, profesión y tecnología; para luego intentar adscribir la contabilidad al cuerpo del conocimiento y definir qué se entiende por contabilidad. Se hará además un análisis de la forma en que se construyen los imaginarios sociales y cómo estos afectan la concepción que se tiene de la contabilidad y del contador público.

De acuerdo en gran parte con María Cristina Wirth (1999), se logra finalmente definir la contabilidad como una tecnología blanda, lo que niega su categoría de ciencia; sin embargo, acepta que las tecnologías son ciencias aplicadas con la capacidad de generar sus propios cuerpos de estudio. Entendiendo, desde la estructura del cuerpo del conocimiento, que la profesión "contaduría pública" resulta principalmente de la aplicación de la sociología y la economía. Y la contabilidad, de la aplicación de la economía, las matemáticas y la metrología social. Así, la contabilidad se entiende como tecnología al servicio de los contadores públicos, como su principal instrumento de medición y procesamiento de información.

Por su parte, Eutimio Mejía-Soto, et al. (2013) realizan un trabajo en el que intentan adscribir la contabilidad al cuerpo de conocimiento y analizan 125 definiciones de contabilidad; a pesar de categorizarla como ciencia social, reconocen que la ubicación de la contabilidad como tecnología es la propuesta que tiene menor peso porcentual [de la muestra tomada], pero es una de las propuestas epistemológicamente mejor sustentadas desde la corriente de pensamiento en la que se mueve Mario Bunge (1960). Reconocen además que esta ubicación de la contabilidad en las tecnologías, lejos de ser un debate concluido, indica que será objeto de reflexión por parte de la comunidad científica. 


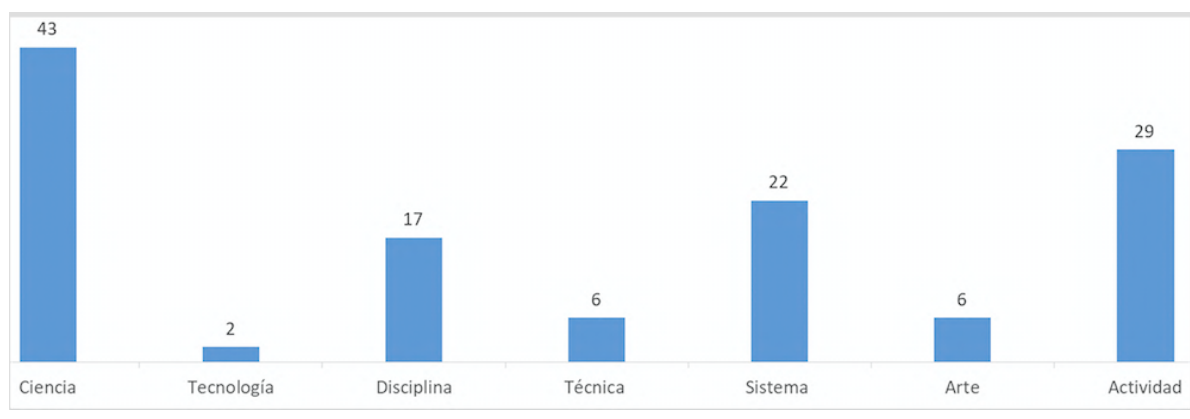

FIGURA 1

Ubicación de la contabilidad en el campo del conocimiento

Fuente: Mejía-Soto et al. (2013)

El presente trabajo surge de las reflexiones y discusiones generadas alrededor de los resultados iniciales de investigación y el material utilizado en la construcción del marco teórico de la investigación mencionada en la nota al pie del título de este trabajo. Con fundamento en la vinculación existente entre contabilidad y sociedad, se introducen postulaciones presentadas desde la sociología en la búsqueda de puntos convergentes que jueguen un papel heurístico, de los que surjan interpretaciones que permitan la construcción de un concepto de contabilidad abordado desde una perspectiva principalmente epistemológica y ontológica, apoyados en la complementariedad de las perspectivas taxonómica y teleológica. Este trabajo busca entonces resolver la problemática que surge alrededor de las múltiples definiciones asignadas a la contabilidad y de su desvinculación con los aspectos sociales, mediante la propuesta de un concepto de contabilidad y de la interpretación de su relación con la sociedad.

En este trabajo se revisaron 136 documentos de investigación contable, 29 de los cuales se seleccionaron para su estudio, análisis, interpretación y discusión. Así mismo, se revisaron 33 textos de sociología y se consideró pertinente introducir 21 de ellos a este trabajo. Finalmente, fue necesario involucrar contenidos de textos de historia de la ciencia y pedagogía como complemento a las ideas trabajadas. Todos los contenidos fueron ampliamente discutidos a la luz de sus puntos convergentes; sin embargo, no se pretende construir el concepto a partir de un análisis estadístico del número de definiciones presentadas por diversos autores según sus categorías (como lo hacen los trabajos de revisión documental), sino a partir de un análisis e interpretación de carácter epistemológico de los argumentos presentados. La construcción de gráficas - como perchas de análisis, tablas de integración, mapas conceptuales y mentefactos - sirve como apoyo en la construcción, la cual lejos de considerarse definitiva, reconoce el esfuerzo de otros investigadores preocupados por el mismo asunto y busca evolucionar anteriores aproximaciones al concepto de contabilidad.

Se utiliza la metáfora como herramienta heurística para avanzar en la aprehensión y reconocimiento de nuevos conceptos, bastante utilizada en las ciencias sociales, principalmente en analogías con las ciencias naturales, las cuales poseen una estructura más consolidada y clara por su antigüedad y relativamente fácil comprensión; para intentar esclarecer aspectos propios de la disciplina contable. No se trata de una simple comparación de características; se trata de una analogía que respeta sus relaciones estructurales con el todo, es un proceso de modelización estructuralista, el cual en coherencia con Roxana Ynoub (2015) hace parte de las cuatro formas de modelar desarrolladas por Georg Friedrich Hegel: modelizaciones mecanicistas, modelizaciones organísmicas/funcionalistas, modelizaciones dialécticas y las modelizaciones estructuralistas.

Se analizaron las demás profesiones cuya estructura resulta más clara con relación a su adscripción al cuerpo de conocimiento; se intentó, en concordancia con el resto de las partes, ubicar cada uno de los conceptos en una jerarquía coherente. Se utiliza la medicina arbitrariamente, pero pudo hacerse con la ingeniería mecánica: las ciencias son física y matemáticas, y la profesión es la ingeniería mecánica, que aplica saberes de la física y las matemáticas para solucionar problemas específicos de su campo de saber y que posee instrumentos como los escáneres, los micrómetros y otros, que el objeto de estudio de los micrómetros (tecnología) es la medición 
y el de la profesión (ingeniería mecánica) es el movimiento. En ese caso, la comparación hubiese sido con el micrómetro, pero para este trabajo no importan el micrómetro en sí y sus características; importa la posición del concepto de "tecnologías" ante los conceptos de "profesiones" y de "ciencia".

\section{Cuestión epistemológica}

Las ciencias sociales han sorteado una incansable lucha por ser reconocidas como tales, a pesar de no poseer las mismas características de las ciencias naturales. Las primeras han surgido como respuesta a la necesidad de reconocer aspectos del sujeto que, se considera, deben ser incluidos en el nuevo conocimiento generado a partir de la investigación. La madurez de las ciencias naturales y su consolidación como fuente de conocimiento hicieron que inicialmente las ciencias sociales buscaran su propia validación mediante un forzado encuadramiento en ciencias como la física, proceso conocido como la "fisicalización de las ciencias" (Echeverría, 1999).

Si bien hay dos enfoques epistemológicos principales para definir la forma como se abordan los objetos de estudio, a saber, el cuantitativo y el cualitativo, las definiciones que giran en torno a su producto, es decir, al nuevo conocimiento o a la ciencia en sí, guardan puntos convergentes que permiten obtener una definición de ciencia que bien puede ser aceptada de manera general. Con base en lo planteado por Bunge (1960), M. Bonifati Kédrov y Aleksandr Spirkin (1968), Carlos Sabino (1992), Germán Vargas-Guillén (2006) y Klaus Jaffe (2012), ciencia puede definirse como el producto de la actividad humana, que busca validez por medio de la sistematicidad y el rigor para generar conocimiento general y verificable de las cosas y hechos que son accesibles al hombre.

De manera un tanto arbitraria, las ciencias pueden separarse en: ciencias formales, ciencias naturales y ciencias sociales y en ellas se puede seguir haciendo otra separación más detallada de los diferentes saberes. Debe reconocerse que en el mundo real las cosas simplemente son con independencia de lo que epistemológicamente se piense de ellas; el intento de separar en ciertas taxonomías algunas cosas del mundo puede generar algunas confusiones y disensos, que no son objeto de este trabajo. La tabla 1 muestra una somera segregación de las diferentes ramas del conocimiento.

TABLA 1

\section{División de las ciencias}

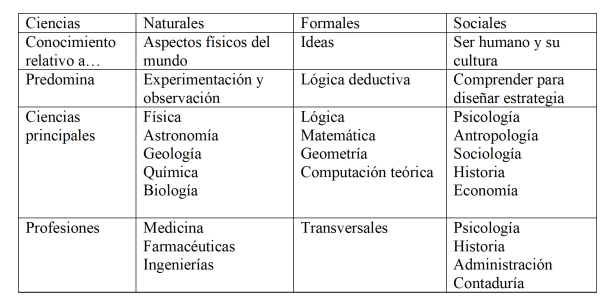

Fuente: elaboración propia con base en Bunge (1960), Taton (1973), Kuhn (1992), Sabino (1992), Ynoub (2015)

Durante la Ilustración, los científicos estaban decididos a disipar la oscuridad de la humanidad mediante el uso de la razón y a evitar conjeturas ligeras; se le dio importancia radical a la obtención de nuevo conocimiento que fuera respaldado por la racionalidad y un método que la garantizara. En el sentido puramente positivista, las ciencias sociales poseen un problema epistemológico al no encontrarse separación clara entre sujeto y objeto; por tanto, en la relación, más bien dada de la forma sujeto-sujeto, se carece de la objetividad requerida para considerar formal y exacto el conocimiento generado, pues el sujeto que estudia la realidad se inmiscuye, a la vez como objeto de estudio.

Sin embargo, la visión netamente matemática y objetiva de la ciencia empezó a ser duramente criticada principalmente al observarse resultados que empezaban a afectar el bienestar de la especie humana. Surgieron 
preocupaciones por la contaminación y la sobreexplotación de los recursos naturales y comenzaron a visibilizarse sus nefastas consecuencias. En este nuevo contexto, cobró valor la idea de que lo subjetivo también cuenta a la hora de hacer nuevo conocimiento y funciona como mecanismo regulatorio del deshumanizado avance del positivismo, al reorientar esfuerzos para lograr desarrollos que considerasen más los aspectos de la faceta humana y su bienestar.

Uno de los principales argumentos de los defensores de las ciencias sociales es que la verdadera objetividad es una fantasía que no pueden lograr las ciencias naturales, debido a que es el mismo hombre quien crea problemas de investigación y en su contexto se presentan las posibles respuestas. Plantean que toda explicación de cualquier fenómeno no es sino la explicación humana del mismo y por consiguiente subjetiva (Nietzsche, 1970; Ynoub, 2015). Los problemas reales no se constituyen como problemas que tal sociedad impone; estos surgen más bien en función del imaginario social de cada sociedad o cada época consideran. Esto no debe confundirse con la idea de que los problemas surgen de la nada; estos surgen de las construcciones pensadas por medio de los símbolos y sus significados (Beriain, 2011) y cobran valor intersubjetivo dentro de los marcos teóricos y corrientes de pensamiento en que son construidos.

Ahora bien, las profesiones pueden verse como la aplicación del conocimiento, es decir, como ciencias aplicadas. En este trabajo se entiende ciencia aplicada como la aplicación del conocimiento generado (ciencia), en la solución de problemas reales en el mundo. Las profesiones juegan este papel mediante el desempeño de individuos especializados en un campo del saber para aplicar tales saberes en situaciones polémicas, construidas de manera específica en cada campo del conocimiento. Así, los conocimientos sobre los que se fundamentan las profesiones (ciencias aplicadas) son las ciencias puras.

En coherencia con lo expuesto desde una perspectiva más bien positivista pero perfectamente válido para la perspectiva cualitativa, Bunge (1960) y Carlos Sabino (1992) explican que las ingenierías son, principalmente, matemática y física aplicada o matemática y química aplicada. La medicina es biología y química aplicada. La administración es matemática, psicología y sociología aplicada. Pero ¿qué es la contaduría pública? ¿Qué es la contabilidad? ¿Qué campos del saber convergen en la contaduría pública y la contabilidad?

Faltaría definir ahora las tecnologías. Se parte de Germán Vargas-Guillén (2006), quien plantea que son la forma contemporánea de dar curso a los saberes en medio de la realidad. Por medio de ella se busca penetrar en la naturaleza o esencia de las cosas para transformarlas sustancialmente. Con la tecnología se intenta construir una forma de ver contemplativamente el objeto de estudio de cada rama del conocimiento. Las reflexiones surgidas de estas observaciones de la realidad han dado como resultado métodos y técnicas taxonómicas para la organización científica, entendidos como "conocimiento tecnológico". Lo anterior puede complementarse perfectamente con lo planteado por Bunge (1960), quien asevera que las tecnologías son más que ciencias aplicadas, debido a su capacidad de generar cuerpos de estudios propios; de donde se deduce que, gracias a esto, muchas tecnologías son confundidas fácilmente con ciencias.

Así, cada profesión posee sus instrumentos con los cuales los individuos leen el mundo, esto es, capturan impresiones provenientes de los objetos de estudio que permitan hacer una representación de su realidad. Estos instrumentos pueden verse como tecnologías que surgen también de la aplicación del conocimiento, es decir, del uso de la ciencia, las cuales sirven para obtener información del objeto de estudio y normalmente son dominadas o controladas en la sociedad por el ámbito político (Gómez-Villegas, 2005). Por ejemplo, los médicos tienen a su disposición el estetoscopio, la máquina de rayos $\mathrm{x}$, la tomografía axial computarizada (TAC), entre otras tecnologías, por medio de las cuales obtienen datos, de los que surge información con la que construyen representaciones útiles para tomar decisiones en la solución de problemas propios de su rama del saber.

De igual manera, los ingenieros poseen metros, teodolitos, cronómetros y otros instrumentos, desarrollados en forma de tecnologías que permiten captar información de sus objetos de estudios, de tal 
manera que cuenten con datos que les permitan tomar decisiones en su accionar profesional. Entonces, ¿cuáles son los principales instrumentos del contador público?

TABLA 2

Aplicación de las ciencias

\begin{tabular}{|c|c|c|}
\hline Ciencia que se aplica & $\begin{array}{c}\text { Biología, química, } \\
\text { matemática }\end{array}$ & $\begin{array}{c}\text { Sociología, economía, } \\
\text { matemática, metrología }\end{array}$ \\
\hline Profesión & Medicina & Contaduría pública \\
\hline $\begin{array}{c}\text { Objeto de estudio de la } \\
\text { profesión }\end{array}$ & La materia viva & $¿ ?$ \\
\hline Instrumento & TAC & $\vdots ?$ \\
\hline $\begin{array}{c}\text { Objeto de estudio de la } \\
\text { tecnología }\end{array}$ & Imágenes & $¿ ?$ \\
\hline
\end{tabular}

Fuente: elaboración propia

Los profesionales tienen a su disposición instrumentos surgidos como resultado de la aplicación del conocimiento y que sirven para obtener información importante para la toma de decisiones y pueden llamarse tecnologías. En algunas profesiones, resulta fácil definir la ciencia, el profesional, el objeto de estudio y los instrumentos con los que se aborda la realidad; en el caso de la contabilidad y la contaduría, de primera mano resulta difícil ubicar estos elementos y dependiendo de esta ubicación, se entenderá la contabilidad y su relación con la sociedad.

\section{Ubicación de la contabilidad en el cuerpo de la ciencia}

En la presente sección se proponen respuestas a los interrogantes planteados en la parte anterior. Se inicia adscribiendo a la contabilidad como una tecnología construida a partir de la aplicación de la ciencia y en el universo mental de las personas, compartida por el colectivo en forma de acuerdo social. En este sentido, cuando un estudiante de contaduría aprende contabilidad, está aprendiendo las reglas y los procedimientos del acuerdo social existente entre los individuos. Un acuerdo de la forma de generar datos, de los que surja información útil para representar la realidad económica. Está aprendiendo la forma de asignar significado a la expresión $\mathrm{A}=\mathrm{P}+\mathrm{C}($ Activo = Pasivo + Capital $)$, por ejemplo.

En coherencia con Horacio López-Santiso (2001), al carecer de realidad física, la contabilidad puede explicarse de la manera anterior. Puede entenderse como una tecnología blanda, un artefacto no físico sino mental, surgido como toda tecnología de la aplicación empírica del conocimiento científico orientada hacia la solución de problemas y que, además, es capaz de generar y desarrollar su propio cuerpo de estudio, esto hace, como ya se mencionó, que las tecnologías en general sean más que ciencia aplicada (Bunge, 1960).

Al continuar con la ruta heurística haciendo analogía con la medicina, la contabilidad puede verse como el TAC o el instrumento mediante el cual el profesional puede capturar datos que interpreta y convierte en información, por medio de la cual tomará decisiones para influir sobre su objeto de estudio. Así, la contabilidad puede entenderse metafóricamente, como aquella gran máquina o artefacto (de índole inmaterial) que permite observar el objeto de estudio tras la lente de diferentes calibraciones (normas o reglamentos contables), la cual finalmente entregará imágenes o representaciones de la realidad. Algunas investigaciones, como trabajo de mejora de la tecnología, se han esforzado por mejorar la resolución de estas "imágenes generadas" por la contabilidad, para tratar de ajustarlas más a cada realidad, en virtud de reconocer la incapacidad de estas imágenes de representar algunas realidades organizacionales proyectadas en las cuentas (Roberts \& Scapens, 2009).

El hecho de que este potente instrumento esté construido en el mundo de las ideas y no en el mundo real, exige una rigurosa estandarización de sus procedimientos para encontrar homogeneidad en la información suministrada entre los individuos. Por esto, se considera también un acuerdo social regulado por las normas; el cual busca, tras las presiones de una sociedad económica y tecnológica desarrollada, su estandarización mundial. 
No se considera coherente definir la contabilidad como ciencia, ya que la ciencia ha sido definida como un cuerpo de conocimiento y la contabilidad en sí no es un cuerpo de conocimiento. En coherencia con Héctor Darío Betancur (2012), se acomoda mejor a la concepción de ciencia aplicada en forma de tecnología con la generación de su propio cuerpo de estudio. Lo anterior pareciera dejar entonces a la profesión contable alejada del carácter científico, pero esto no es así. El contador público, en este contexto, puede entenderse como un profesional que hace uso de la ciencia, principalmente de la sociología y la economía (sin desconocer la matemática, la lógica y otras), y que posee a su servicio ese poderoso instrumento llamado contabilidad. Por tanto, quien debe adquirir el carácter de científico no es el instrumento, sino el actor, el profesional. Pretender llamar ciencia a la contabilidad puede resultar tan incoherente como decir que "la generación de imágenes con el TAC" es la ciencia que fundamenta la medicina.

Así las cosas, las funciones de interpretar, estudiar y controlar no son funciones propias de la contabilidad, sino de los individuos: el contador y los propietarios, y lo hacen apoyados en la información que se genera con el instrumento "contabilidad" intencionalmente para tal fin. No resulta coherente decir que la contabilidad "interpreta”, más bien, "representa" bajo ciertas lógicas; el proceso de interpretación es propio de los sujetos cognoscentes, no de los instrumentos.

Surgen entonces dos tipos principales de contadores científicos (igual para las demás profesiones): los que aplican sus trabajos en el desarrollo de la tecnología (la contabilidad) como desarrolladores de instrumentos y tecnología; y los que aplican su trabajo en el contexto social, al poner la contabilidad a su servicio en aras de interpretar situaciones sociales y tomar decisiones contribuyentes a su mejoramiento. Así mismo, hay profesionales contables que hacen uso de los conocimientos y las tecnologías para solucionar problemas profesionales dentro de su campo de saber, sin abordar problemas científicos.

Ahora bien, luego de analizar, interpretar y discutir sobre el objeto de estudio de la contabilidad como instrumento, en coherencia con Jack Alberto Araujo-Ensuncho (2007), se propone la circulación de los recursos en la sociedad en general, entendiendo recursos como el conjunto de bienes disponibles y valiosos, por lo que esto desborda la esfera de lo financiero e involucra bienes como el aire y el agua, entre otros. Conscientes de la ausencia de acuerdo teórico en la definición de este objeto, se busca sustento en la idea referente al artefacto mental que se ha desarrollado (la contabilidad), es capaz de activarse al momento de identificar que hay circulación de recursos (becho económico) y se puede medir por diversos métodos, para la que ha sido "calibrada" por medio de la norma, para luego clasificar en una taxonomía propia de los elementos involucrados en las relaciones sociales, en razón de generar un registro o memoria de carácter histórico de estas circulaciones y sus efectos.

Ahora resulta necesario esclarecer el objeto de estudio de la contaduría pública. Por ejemplo, el objeto de estudio para la profesión medicina es la materia viva. Si la contaduría pública se entiende como sociología (principalmente) aplicada, en concordancia con Seoane-C. (2006) y Dubet (2012) puede evidenciarse que la definición de un objeto de estudio es también una cuestión no definida para la misma sociología. Se plantea entonces de manera inicial que la relación de los agentes económicos es el objeto de estudio de la contaduría pública. Se reconoce que este es un terreno aún no recorrido por este trabajo y se plantea para futuras discusiones.

En este sentido, debe considerarse que en el mundo hay personas naturales y jurídicas, que poseen el dominio de ciertos recursos que arriesgan a la circulación motivados por el afán de su maximización. La contabilidad, metafóricamente funcionaría como aquella máquina dotada de una lente que se puede cambiar para dar diferentes calibraciones (norma), que captura la información generada en la sociedad por la circulación de esos recursos. Esto, a su vez, involucra la política y el desarrollo social en este análisis, debido a que, por medio de esa información y posterior interpretación, se tomarán decisiones que tendrán efectos directos en la misma sociedad, como decisiones de inversión, de despidos, de venta, de compra, de asignación de presupuestos y de pago de tributos, entre otras. 
Esta última concepción exalta el carácter de lo público en el profesional contable, como garante de la información veraz y confiable para la tranquilidad de todos los actores involucrados en un grupo social. En este sentido, la profesión contable posee gran relevancia económica y política en la sociedad, debido a que por medio de ella se busca generar confianza, no solo en las relaciones entre inversores, clientes, proveedores, entre otros; sino que los bienes públicos se conserven y sean aprovechados por todos. Baker (2009) plantea un interesante trabajo en el que se intenta conocer el significado de lo público mediante el examen de la ideología de la profesión contaduría pública estadounidense.

Con la información contable se calculan el Producto Interno Bruto y cualquier otro indicador económico, se calcula el Índice de Precios al Consumidor (IPC), que normalmente sirve de referencia para definir el valor del salario mínimo mensual en varios países, se decide asignar presupuestos a las cárceles y a los hospitales públicos, se asignan recursos a la educación y a las fuerzas militares, es decir, se construye sociedad. Se devela entonces la importancia del contador como garante de que lo público sea respetado como bien común, al igual que lo privado, como bien privado. Así, la información contable en la sociedad sirve para que por medio de ella los individuos se formen representaciones de la circulación de los recursos que sirve como fundamento en la toma de decisiones para la construcción de la misma sociedad. Finalmente, la tabla 2 puede redefinirse de la siguiente manera:

TABLA 3

Adscripción de la contabilidad al cuerpo de conocimiento

\begin{tabular}{|c|c|c|}
\hline Ciencia aplicada & $\begin{array}{c}\text { Biología, Química, } \\
\text { Matemática }\end{array}$ & $\begin{array}{c}\text { Sociología, Economía, } \\
\text { Matemática, Metrología }\end{array}$ \\
\hline Profesión & Medicina & Contaduría Pública \\
\hline $\begin{array}{c}\text { Objeto de estudio de la } \\
\text { profesión }\end{array}$ & La materia viva & $\begin{array}{c}\text { Relación de agentes } \\
\text { económicos }\end{array}$ \\
\hline Instrumento & TAC & Contabilidad \\
\hline $\begin{array}{c}\text { Objeto de estudio de la } \\
\text { tecnología }\end{array}$ & Imágenes & Circulación de recursos \\
\hline
\end{tabular}

Fuente: elaboración propia

Resumiendo, la ciencia puede entenderse como un cuerpo de conocimiento con características especiales, la cual es utilizada por las profesiones en la búsqueda de soluciones a problemas particulares en cada campo del saber (ciencia aplicada). Cada profesión ha desarrollado una serie de instrumentos en forma de tecnologías surgidas también de la aplicación del conocimiento, tan especializadas que forman su propio cuerpo de estudio. La contaduría pública se adscribe a las profesiones y utiliza principalmente la sociología y la economía. Por otra parte, la contabilidad se adscribe a las tecnologías, desarrolla su propio cuerpo de estudio y puede evolucionar de acuerdo a las necesidades planteadas por los actores sociales.

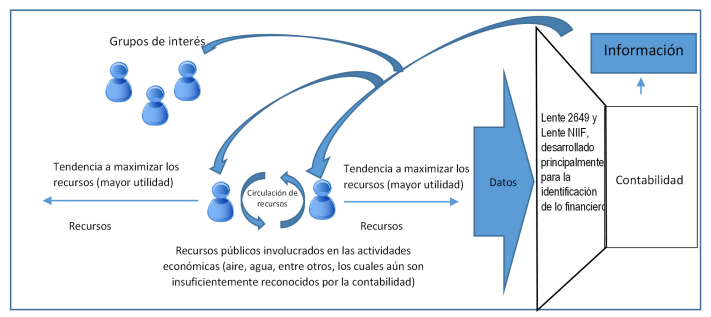

FIGURA 2

Contabilidad y circulación de los recursos

Fuente: elaboración propia

Lo planteado evidencia la necesidad de hacer una contextualización de lo entendido por sociedad y propender por realizar interpretaciones que permitan lograr una mejor construcción del concepto de contabilidad, en virtud del reconocimiento del carácter político y social de esta tecnología. En este sentido, se incluye en este trabajo una revisión desde una perspectiva castoriadisidiana (desde los imaginarios sociales) 
de diferentes aspectos de las relaciones sociales, con la intención de hallar puntos convergentes que permitan un mayor alcance en la construcción de este concepto.

\section{Contextualización para la definición de contabilidad desde los imaginarios sociales}

Una de las discusiones más importantes de la epistemología en contabilidad es la definición de su objeto de estudio en el campo social. Este gran campo encierra en sí mismo una serie de constructos o imaginarios, que se hacen colectivos no de manera general o universal, sino, más bien validados por ciertos sectores de la sociedad o de las comunidades.

El problema resulta un tanto más interesante al poder observar que una comunidad (la que a la vez es otro constructo imaginado, si se mira desde un enfoque castoriadisiano) es la encargada de dar validez a una serie de ideas o construcciones colectivas, que no pueden dejar de estar influenciadas por las cualidades del imaginario en que se contienen; así, cada sociedad construye sus propias normas de interpretación de lo real. Más aún, "existe una dimensión política derivada del cuestionamiento de la certidumbre e interpretación alternativa de \#lo real\#” (Randazzo, 2011). En ese sentido, Cornelius Castoriadis (1975) resalta la importancia del reconocimiento de la sustantividad y autonomía de lo imaginario en la vida colectiva. Idea que inmiscuye obligatoriamente lo político.

Toda época posee sus imágenes con las que hace un dibujo de la realidad. Mediante las metáforas, los individuos constituyen un tejido semántico con el que cuentan su experiencia y alzan por encima de la realidad bruta y natural las imágenes generadas, bosquejan una cierta organización semántica de la experiencia que los rodea; estas imágenes constituyen la base para la búsqueda del sentido de las cosas y de esa forma, salvan el sentido de la convivencia social respecto a la confusión que genera todo accionar humano (SánchezCapdequí, 2011). Surge entonces la idea de la experimentación de un mundo social del que se producen significaciones compartidas, por tanto, aquello que finalmente es considerado "realidad social" termina siendo la validación colectiva de determinadas relaciones sociales, estilos de pensar, hacer, juzgar, compartir, convivir, entre muchos otros aspectos relativos a la vida en conjunto de seres gregarios (Baeza-Rodríguez, 2011).

En este sentido, "el constreñimiento de lo simbólico se disimula detrás de la identidad imaginada" (Augé, 1996, p. 17). Se quiere decir con esto y en concordancia con Hannah Arendt (1994), que las sociedades son construcciones imaginadas, que existen solo como una condición de aceptación de esta condición, dada en los individuos. De esta manera, un ciudadano considerará compatriota (o de los suyos) a cualquier desconocido que posea su misma nacionalidad.

A partir de lo anterior, la sociedad puede definirse como un grupo de individuos, que comparten en cierta medida, una misma cultura y costumbres; se relacionan en un mismo entorno, se apoderan de cierta posición geográfica en cierto tiempo y desarrollan sentido de pertenencia por las cosas que los rodean, características propias de animales territoriales. En cierta medida, las sociedades comparten lazos ideológicos, económicos y políticos imaginados y utilizados para su propio fin, regulados en su madurez por reglas jurídicas definidas por las costumbres.

En coherencia con lo anterior, Enrique Carretero-Pasin (2011) y Benedict Anderson (1993) definen las sociedades como una comunidad política imaginada como inherentemente limitada y soberana. La concepción de imaginada obedece a que incluso los miembros de la nación más pequeña no conocerán jamás a la mayoría de sus compatriotas y, sin embargo, en la mente de cada uno vive la imagen de su comunión.

Esto indica que el vínculo social es una cuestión construida y, por tanto, modificable. Desde el enfoque de Delia Guiliani (2015), por medio de las instituciones y de los sistemas de mantenimiento del Estado, la sociedad hereda una serie de costumbres y de concepciones que muchas veces pueden ser injustas o desiguales y, sin embargo, son legitimadas por medio de esa herencia. Se debe analizar, por tanto, que son heredadas, 
dadas, naturalizadas en la comunidad; no son algo innato, por consiguiente, son posibles de modificar, visibilizar y democratizar. Esto seduce a la reflexión sobre los aspectos aceptados en las prácticas contables y quizás validados socialmente por medio de la herencia y la tradición, pero que tal vez generan resultados desequilibrados socialmente.

Desde la perspectiva de Pierre Bourdieu, Jean-Claude Chamboredon y Jean-Claude Passeron (2002), se plantea que muchos de los aspectos que dan forma a la sociedad (hechos sociales) pueden ser estudiados como "cosas", sin intentar explicar tal cual lo que es el fenómeno ocurrido, sino para verlo como un dato, como algo posible de observar y sobre lo que se puede empezar una investigación o la creación del objeto. Así mismo, se debe tener en cuenta su relatividad y sobre todo la influencia que pueden llegar a tener los demás imaginarios en el mismo (Bauman, 2002). Debido a la misma naturaleza social de la contabilidad, la construcción de cualquier aspecto alrededor de ella, tal como un problema de investigación en esta disciplina, exige que este se mire teniendo en cuenta la relación existente entre la contabilidad, la sociedad y los aspectos surgidos de esta relación, entendiendo todo en su contexto, como cosa observable.

La construcción de representaciones de la realidad social, lo cual incluye lo financiero, lo económico, el bienestar, los recursos, la riqueza, entre otras materias, es una tarea de las ciencias sociales materializada en gran parte por medio de la contabilidad. Esta representación puede llevarse a cabo solo por medio del reconocimiento de las estructuras y las propiedades emergentes de sus objetos de estudio, de aquellos objetos que otorgan sentido a sus dominios de discursos y campos de aplicación (Machado, 2009). La contabilidad, entonces, tiene la función de representar cuestiones imaginadas y validadas de manera colectiva.

En este sentido, la contabilidad es un hecho social y puede llegar a ser entendida como un constructo humano, por tanto, influenciada por la cultura. La existencia de diversas culturas - que construyen sus propias representaciones de lo real, por medio de un requerimiento de información- agrega diversos matices a la contabilidad. Esta está en busca de su validación por medio de los diversos escenarios sociales. Por eso, el mundo económico está tras un constante intento de universalización de la contabilidad, en el que confluyen aspectos muy generales como lo económico y otros de naturaleza más bien particular, como la misma cultura y las costumbres.

Además, se debe tener en cuenta el carácter heterónomo de la contabilidad (Cuevas, 2008), la cual, antes que orientada por sus razones propias, vive en constante evolución en su afán de satisfacer las necesidades planteadas por la sociedad. Al entender la contabilidad de esa forma, se puede aseverar que esta está replanteando su orientación constantemente hacia las exigencias de cada sociedad (Chatfield, 1977; Kaplan, 1984; Lee \& Parker, 1979; Littleton \& Zimmerman, 1962; Tua-Pereda, 1988).

El desarrollo histórico de la contabilidad demuestra cómo esta se ha venido desarrollando paralelamente a las exigencias de la sociedad. Así se puede apreciar el surgimiento de diversas escuelas contables, que pretenden entenderla desde su cosmovisión individual, tal como puede notarse en los trabajos de María Teresa MéndezPicazo y Domingo Ribeiro-Soriano (2012), Amílcar Laya (2011) y Elsa de Larrea y Dávalos (1997). De la misma manera, surgen conceptos de contabilidad tan variados como las necesidades a las que responde. Esto último se puede apreciar en el trabajo de Jorge Tua-Pereda (1988), quien realiza un estudio del concepto de contabilidad a partir de sus definiciones.

Cada comunidad, contextualizada por sus costumbres y creencias, otorga validez a cierto tipo de rutinas profesionales y encuentra discordancia con la validación otorgada por otras comunidades. Lo importante hasta este momento es comprender cómo un imaginario social (la contabilidad) es influenciado a la vez por diversos imaginarios que le dan forma a la sociedad (otro imaginario social); comprender cómo la sociedad como imaginario es a la vez construida y validada por otro conjunto de imaginarios que guardan relación entre sí. Por eso, la relación entre sociedad y contabilidad no puede entenderse de manera lineal sin caer en la falta de completitud, esta debe entenderse más bien como recíproca y complementaria y otorgar el carácter de heterónomo no solo a la contabilidad, sino a la sociedad misma, pues, por medio de la información contable, los individuos forjan la sociedad. 
Basados en la información generada por procedimientos y enfoques validados socialmente, los individuos, mediante su ejercicio político, toman decisiones para dar forma a la colectividad en que se congregan (sociedad). Al aterrizar el punto de vista de Zygmunt Bauman (2002) a los aspectos contables, se puede decir que la información contable es comprendida e interpretada de manera específica en cada momento de la historia y determinada por la tradición y las costumbres. Con la información contable se cierra o inaugura un hospital público o privado, se asigna presupuesto para la educación, la guerra o la investigación, se despide o contrata, se define la edad de pensión de empleados y se toman otras decisiones que afectan directamente el bienestar de individuos en la sociedad; a la vez, estas decisiones han sido influenciadas por los imaginarios colectivos de la misma sociedad. Por eso, resulta imposible la separación de política y contabilidad, y el estudio de esta resulta un problema sociológico que comprende la relación entre contabilidad y sociedad de manera recíproca y cíclica.

Lo anterior se fortalece en las ideas de Michel de Certeau (2000), que se pueden aterrizar al discurso contable en busca de la comprensión de la disciplina en la sociedad. De Certeau plantea que las convicciones de lo que representa al individuo no se expresan en convicciones directas, sino mediante el rodeo de lo que se supone que otros deben creer. Esta posición argumenta que la validez de las creencias se refleja en el otro, pero no en el otro de manera directa, sino en el supuesto colocado en el otro. De este modo, se puede entender que la contabilidad les otorga validez a las decisiones económicas tomadas en la sociedad y la sociedad les otorga validez a las formas de representar esa realidad por medio de la contabilidad, auspiciadas por los pensamientos supuestos, de una parte, de que los contadores logran efectos sobre la realidad por medio de sus rigurosos sistemas de medición y valoración y, por otra, de que la sociedad es como es, porque se construye con la información contable. En palabras de Michel de Certeau: "cada uno por su cuenta, espera del otro una garantía que dé consistencia a su simulacro" (2000, p. 204).

Por otra parte, Beatriz Sarlo y Carlos Altamirano (2002) plantean como problema ontológico el concepto social de identidad: primero, como razón, en virtud de la cual son una misma cosa en la realidad y segundo, como aprehensión del entendimiento con que cosas que son realmente distintas se tienen por una misma cosa. Esto plantea una discusión que se mueve en la palestra entre las corrientes esencialistas y constructivistas por una explicación racional de los fenómenos sociales. Se trae a colación el anterior enfoque en aras de encontrar claridad en lo que se intenta plantear hasta el momento: el problema ontológico de la contabilidad ante una sociedad imaginada.

Desde la misma visión de Beatriz Sarlo y Carlos Altamirano (2002), la contabilidad se puede entender como cosa dada en la realidad (visión esencialista) o como cosa construida, dada en el intelecto de los individuos y por tanto, susceptible de modificación subjetiva (visión constructivista). En coherencia con los argumentos presentados hasta el momento, una visión constructivista de la contabilidad puede explicar mejor algunos sucesos que encierran cierto grado de la responsabilidad de la contabilidad para con la sociedad y el aporte que pueda darle a la sociedad y a la humanidad en un mejor sentido para la vida conjunta e individual (Gómez-Villegas, 2011).

Entender la contabilidad como "cosa construida en el intelecto de los individuos" seduce a la preocupación por entender los factores determinantes de los criterios con los que se construye. Como ya se mencionó, estos factores normalmente son impuestos por la sociedad enmarcada en un modelo económico y muchas veces responden a los requerimientos de los organismos de poder y, por ende, del gran capital; así se alejan muchas veces de la responsabilidad intrínseca de dar cuenta de la utilización de todos los recursos relacionados con las unidades económicas. Hoy son precarias, si no nulas, las capacidades de la contabilidad de informar sobre el uso de bienes públicos utilizados por las organizaciones, como el aire, el suelo, los bosques, el agua pura, entre otros bienes de uso común, que se ven afectados por la existencia de organizaciones económicas propiedad de particulares, necesarias para el desarrollo económico.

En el contexto social, la contabilidad es la base para construir la representación de verdades con las que se edifica la sociedad por medio de los imaginarios sociales. En palabras de David Cooper (1980), esta puede 
ser vista como un medio para sostener y legitimar los acuerdos sociales, económicos y políticos y según Peter Miller y Ted O'Leary (2009), esta aporta incluso a la construcción de la persona gobernable.

En la concepción constructivista de este problema, resulta legal cuestionarse sobre la forma que la sociedad le da a la contabilidad, con especial importancia en las consecuencias generadas en las personas que conforman la sociedad. El enfoque constructivista deposita la responsabilidad de los resultados en los individuos y entiende los sucesos como algo construido, no como condición dada. Así la comunidad puede estar legalizando, por medio de la contabilidad, el accionar "desequilibrado" de algunos grupos. Aquí salta a la vista de manera natural el rasgo eminentemente político y sociológico de la contabilidad.

Por todo lo expuesto, resulta incoherente construir un concepto de contabilidad sin mirar el contexto en el que se desarrolla. Resulta necesario tener en cuenta la sociedad y el significado de la contabilidad en la misma. Si la contabilidad es concebida como un acuerdo social, se debe considerar la manera como este se da en la sociedad y la influencia que poseen recíprocamente.

La sociedad ha tenido varias connotaciones a través del tiempo desde la esclavitud hasta la evolución tecnológica y la libertad individual. Estos modelos sociales son construcciones imaginadas que generan una idealización de la sociedad y sus componentes. Hannah Arendt (2003) plantea que el hombre desde esta perspectiva se divide en tres aspectos: labor, trabajo y acción. La labor es lo que el hombre hace naturalmente para vivir, como comer, dormir, entre otras. Trabajo es entonces la fabricación o transformación de materia, que está conformada por acciones que no hacen parte del constantemente repetido ciclo de la vida de la especie; representa un artificial mundo de cosas claramente distintas de todas las circunstancias naturales y la acción es el desarrollo humano en su plenitud.

La sociedad actual está marcada por el desarrollo y la consolidación del sistema capitalista occidental y, en consecuencia, por las disputas de las grandes potencias por territorios, materias primas y mercados consumidores. Se caracteriza por la tendencia a la integración cultural. Predomina el sistema de gobierno republicano y se ha dado paso al desarrollo de la tecnología y la mejora en la calidad de la vida humana. La influencia de la iglesia en aspectos políticos es relativamente menor.

Entender los aspectos sociales como algo construido a partir de los imaginarios, permite inferir que la historia - que funciona como un aspecto relevante en la construcción de la sociedad - no es vista como verdad, sino como una verdad construida por quien la cuenta (Arendt, 1995). Estos constructos surgidos a partir de la historia, sirven a su vez como orientadores en la construcción del imaginario que orienta la constitución de la sociedad, como validadores de las condiciones actuales y como generadores de valor social en el marco de la sociedad que sustentan.

Lamentablemente, el imaginario social formado en torno a la contabilidad ha permitido entenderla como la responsable de informar sobre los recursos financieros de las organizaciones y de cierto modo se ha dejado de lado la necesidad de informar acerca de los recursos de otra índole, como la utilización de los recursos naturales, el aprovechamiento y conformación del capital intelectual, el impacto social de la organización, la responsabilidad de la información contable en las representaciones constituyentes del imaginario social, entre otros.

Lo anterior ha generado una peyoración de la profesión contable y una ignorancia generalizada en la misma comunidad contable acerca de la naturaleza de la contabilidad y de la sociedad. Esta, al exigir de los contadores públicos personas actualizadas, capaces de responder ante la velocidad de las transacciones, y medir su eficiencia a partir de la capacidad de respuesta ante problemas legales-instrumentales ha reducido la esencia profesional a un mero proceso de carácter legal-instrumental (Bachelard, 1973). La organización demanda del contador público principalmente la habilidad de lidiar con los organismos de control, para buscar legitimidad por medio de su representación.

Esto ha permeado además la educación contable; con sus excepciones, aún se puede evidenciar un afán por aplicar técnicas que buscan más el adiestramiento en las prácticas contables, mediante un proceso repetitivo y de memorización, carentes de un enfoque crítico que le permita al estudiante comprender el impacto generado 
por la información procesada. El entorno plantea exigencias que hacen que se desdibuje la capacidad del sistema universitario (Gracia-López, 2006) para la generación de nuevo conocimiento, lo que debilita la identidad y la función reconocida en la universidad como promotora de reflexión, crítica y transformación (Gómez-Villegas \& Ospina-Zapata, 2009).

El ambiente que puede notarse en muchas universidades es que el estudiante se siente satisfecho si aprende a reproducir el sistema de registro dentro de una lógica legalista y normativa, pero se deja de lado el trasfondo social que posee la contabilidad, se entiende en una nebulosa los procesos de investigación en contabilidad y no se tiene lo suficientemente clara la vinculación de esta con la política, la sociología y, por ende, con la vida de los individuos.

Por tanto, el estado ontológico de la contabilidad en un contexto de sociedades imaginadas, puede definirse como un acuerdo social, una construcción del intelecto que encuentra validez en la forma de los individuos de construir un concepto de lo real. Esta construcción es diversa entre grupos de individuos y busca su estandarización en un proceso que involucra una confrontación que trasciende lo netamente económico y toca de lleno lo cultural, lo histórico y aquello que se entiende como "vida del individuo". Consonantemente, Gabriel Rueda-Delgado (2010) expresa que la convergencia contable resulta de una serie de contextos sociales, políticos, económicos y economicistas que continúan confiando en la racionalidad del cálculo y la representación contable como herramienta neutral y objetiva, libre de todo juicio de valor y sesgo con ideología alguna; esta concepción limita a la contabilidad de toda posibilidad de jugar un papel más representativo ante eventos que no sean claramente contables.

Finalmente, se puede decir que la contabilidad y la sociedad son al tiempo independientes e interdependientes. Esta dicotomía se explica a partir de la aceptación de un carácter heterónomo de ambas, esto es, que cada una influye de manera directa sobre la otra para darle forma según sus requerimientos; sin embargo, poseen sus propios fines y desarrollan modelos, concepciones e interpretaciones de lo real de manera independiente, las cuales finalmente terminan siendo validadas social y mutuamente. Por tanto, el estudio de la contabilidad debe hacerse teniendo en consideración la relación existente entre ella y los demás aspectos (también cuestiones imaginadas y construidas) de la sociedad.

\section{Construcción del concepto de contabilidad}

En virtud de lo esbozado hasta el momento, es posible abordar la construcción de un concepto de contabilidad. Este pretende abordarse desde cuatro aspectos principales: epistemológico, ontológico, taxonómico y teleológico. Lo epistemológico ya ha sido abordado al definir la ubicación de la contabilidad en el cuerpo de la ciencia y otorgarle un carácter de tecnología blanda. Los otros tres aspectos se abordan desde la metodología de construcción de conceptos propuesta por Héctor José Sarmiento-Ramírez (2007).

Desde lo ontológico, se puede decir que la contabilidad es una de las tecnologías blandas, las cuales se consideran constituidas por los conocimientos y disciplinas de las interacciones humanas. Estas tecnologías por su carácter inmaterial, pueden darse en forma de acuerdo social, es decir, un conjunto de reglas, normas, principios y procedimientos reguladores del actuar de las personas en el uso de estas tecnologías. 
TABLA 4

Construcción del concepto de contabilidad

\begin{tabular}{|c|c|c|c|}
\hline \multirow{3}{*}{ 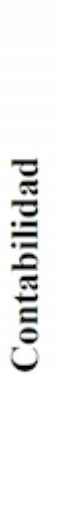 } & Ontológico & Taxonómico & Teleológico \\
\hline & $\begin{array}{l}\text { Tecnología blanda, Instrumento } \\
\text { mental, Acuerdo social, Artefacto } \\
\text { mental }\end{array}$ & $\begin{array}{l}\text { Financiera, } \\
\text { ambiental, social, } \\
\text { de gestión, pública, } \\
\text { forense, tributaria }\end{array}$ & $\begin{array}{l}\text { Dejar memoria } \\
\text { histórica } \\
\text { Interpretar la } \\
\text { realidad social } \\
\text { Estudiar la } \\
\text { circulación de los } \\
\text { recursos } \\
\text { Control } \\
\text { Bienestar general }\end{array}$ \\
\hline & \multicolumn{3}{|c|}{$\begin{array}{l}\text { Addendum: metrología, matemáticas, economía aplicadas y que vincula de } \\
\text { manera intrínseca aspectos de lo público }\end{array}$} \\
\hline
\end{tabular}

Fuente: elaboración propia a partir de la metodología de Héctor José Sarmiento-Ramírez (2007)

La contabilidad puede entenderse como ese conjunto de acciones fundamentado en reglas para su accionar compartido por una comunidad. La estandarización entonces es el esfuerzo por generalizar un conjunto particular de reglas con la intención de orientar el comportamiento de los contadores a la hora de procesar la información relativa a las organizaciones y de los usuarios de la información; sin embargo, se reconoce que esta estandarización, en vez de responder a los intereses de la sociedad, responde más bien a los intereses de ciertos grupos de poder en ella, por lo que puede ser entendida además como mecanismo de poder.

Se menciona esto último gracias a la preocupación contenida, en la idea de que, debido a la economía de esfuerzos natural en los seres vivos, se ha permitido imaginar socialmente a la contabilidad como el sistema que se usa principalmente para entregar información a determinado agente hegemónico. Esto confunde los intereses del agente con los intereses de la contabilidad. Tal ha sido el caso del aspecto tributario en Colombia. Si el Estado en su capacidad de ejercer poder, exige ciertas características de la información contable, la comunidad en general puede llegar a entender al contador como un "trabajador del Estado pago por la empresa privada”. Así se asume, en el contexto general (social), como válida información que ha sido procesada en un contexto particular (lo tributario).

Lo preocupante es que siempre habrá agentes hegemónicos que exigirán información de cierto tipo por medio de ciertas regulaciones y la sociedad no debe permitir que la contabilidad pierda su orientación principalmente social, la cual debe hacerse de manera tal que pueda satisfacer a todas las partes interesadas: gerentes, stakeholders, clientes, proveedores, entidades financieras, Estado y empleados, entre otros.

En cuanto al aspecto taxonómico, se definieron los diferentes enfoques que puede tomar la contabilidad: social, ambiental, financiero, forense, de gestión, público, tributario, entre otros. Aquí se plantea una discusión que no ha sido abordada del todo aún. Es la cuestión de si hay una contabilidad general que sea capaz de rendir información neutral, que pueda ser depurada para cada usuario de manera posterior, pero si es neutral en un espacio construido socialmente en el imaginario de los individuos: ¿lo es desde qué sentido? Se considera que a pesar de ser producida en la empresa y con presupuesto de la empresa, la contabilidad debe rendir información teniendo en cuenta sobre todo el impacto que se generaría en la sociedad. Sin embargo, como se ha podido corroborar en el hacer empírico, termina siendo hegemonizada por la organización, el Estado y los grupos de poder.

Desde lo teleológico, se entiende que la contabilidad tiene como fin dejar memoria histórica de las transacciones comerciales y no comerciales, para la interpretación de la realidad económico-social y conocer la circulación de los recursos mediante el análisis de estas memorias (lo que le da el carácter de retrospectiva), con el ánimo de controlar los recursos en la búsqueda del bienestar (prospectiva). La información contable 
debe contribuir al entendimiento social, es decir, a la obtención de acuerdos entre los participantes en la comunicación acerca de la validez de una emisión (Rueda-Delgado, 2012).

Adicionalmente, se puede decir que la contabilidad es matemáticas, economía y metrología aplicadas. Se reconoce en la contabilidad, como en todos los demás aspectos intelectuales, que el conocimiento confluye de manera compleja; sin embargo, se puede decir que las ciencias mencionadas son las que principalmente le dan cuerpo a la contabilidad. De manera más general, el contador público utiliza la sociología y la economía, junto con la contabilidad para accionar en el diario operar de su profesión.

Si bien la metrología se ubica principalmente en el campo de las ciencias físicas, se propone una extensión de su concepto hacia un alcance en aspectos sociales. Esta ciencia se encarga del estudio de los sistemas de pesos y medidas y si se revisa detenidamente el proceso como se da la medición de cualquier magnitud, se pueden establecer relaciones con los procesos de medición de aspectos económicos y sociales. La contabilidad en su fase de medición utiliza procedimientos de reconocido valor técnico, lo que permite asignar valor a los eventos económicos, en coherencia con Héctor Mora-Nawrath (2017), para generar un dato que posee potencial heurístico, pero no como un pleonasmo de la realidad. En ese sentido, el dato requiere ser interpretado, lo que plantea el problema de fondo de cualquier medición: la producción del número como representación del concepto (lo que a su vez contribuye a la construcción de los imaginarios). Desde este punto de vista, se considera entonces que el estudio de estos procedimientos contables de asignación de valor pertenece inherentemente al campo de la metrología. Este punto deriva múltiples interrogantes epistemológicos que deben ser abordados en trabajos posteriores, ya que no constituye el objetivo de este trabajo.

Con base en todo lo expuesto, se propone la siguiente definición de contabilidad: es una tecnología blanda, por tanto, un instrumento de índole mental construido y compartido por una sociedad, lo que la convierte en acuerdo social que toma forma de disciplina, puede dividirse en contabilidad social, tributaria, forense, de gestión, pública, ambiental, entre otras y se usa para dejar memoria, interpretar la realidad y estudiar la circulación de los recursos en la búsqueda de su control y el bienestar social general. Además, resulta de la aplicación de la metrología en lo social, la matemática y la economía principalmente e involucra intrínsecamente aspectos de lo público de la sociedad.

Por último, cabe resaltar la diferencia entre contabilidad y contaduría pública, al otorgar a la contabilidad un carácter disciplinar y a la contaduría un carácter profesional. La contaduría pública es la profesión que aplica sociología, y economía principalmente y que cuenta con una tecnología desarrollada socialmente llamada contabilidad, junto con estadística, matemática, principalmente financiera, entre otras.

\section{Conclusiones}

Es necesario preguntarse por la relación existente entre la sociedad y la contabilidad y el papel que juegan los diferentes actores en ella, por la responsabilidad del profesional contable al momento de informar sobre la circulación de recursos y sobre el papel constructor desempeñado por la contabilidad en la sociedad. En este contexto, se puede decir que contabilidad y sociedad son mutuamente complementarias y heterónomas, pues cada una influye en la construcción de la otra. Así, antes que un cuerpo de conocimiento independiente, la contabilidad es un conjunto de ideas forjadas bajo la presión misma de las exigencias sociales de cada época. En ese mismo sentido, la información generada por medio de la contabilidad sirve como base para generar representaciones de la circulación de los recursos, hacerse imágenes de la sociedad y tomar decisiones que repercutirán en sus características. Por tanto, la información contable es la base sobre la cual se decide sobre aspectos de índole económico-social.

Contabilidad y sociedad comparten otra característica común: ambas son constituidas por medio de imaginarios sociales, es decir, estas son ideas compartidas por una comunidad en forma de consciencia colectiva. Esta relación entre sociedad y contabilidad fuerza las intenciones a considerar obligatoriamente 
una concepción sociológica de la contabilidad, como responsable de la influencia de la información en la toma de decisiones económicas y políticas. Entender la contabilidad como "cosa construida en el intelecto de los individuos" debe obligatoriamente seducir a la preocupación por conocer y comprender los factores determinantes de los criterios con los que se construye. Los contadores públicos poseen gran responsabilidad en el desarrollo de una profesión que puede entenderse como ejercicio político. Quedan sobre la palestra discusiones sobre el objeto de estudio de la profesión contable.

Lamentablemente, la herencia obtenida desde el accionar empírico fortalecido por muchos años de trayectoria en el actuar disciplinar ha desvirtuado el papel del profesional contable. La contabilidad ha sido incubada en rutinas y monotonías, avariciosamente conservadas, signada por el conformismo y la constancia de lo legal-instrumental, hasta el punto de influir en el imaginario social a través de una concepción de oficio en las prácticas contables, peyorando la concepción de la profesión, al reducirla al simple registro para informar y validar las transacciones comerciales. Esto permea el actuar universitario influenciado a la vez por la visión empresarial de la educación. Deben por otra parte, reconocerse los avances de la educación contable desde la perspectiva crítica que ha logrado mitigar tal efecto.

La contabilidad puede entenderse como tecnología blanda, instrumento de índole mental compartido por un colectivo, acuerdo social, con el potencial de generar representaciones que pretenden dar cuenta de aspectos sociales, tributarios, forenses, de gestión, públicos, ambientales, entre otros y tiene como fin dejar memoria de las transacciones comerciales y no comerciales, interpretar la realidad y estudiar la circulación de los recursos en busca de su control y del bienestar social general. Posee repercusión en lo público de manera intrínseca. Esta definición de contabilidad no se considera terminada y permite aportes que fortalezcan su contenido.

La contabilidad se puede adscribir al cuerpo de conocimiento como tecnología blanda, no como ciencia. En el ámbito de las ciencias están las matemáticas, la sociología y la economía principalmente que, aplicadas en la solución de problemas, dan origen a la profesión contaduría pública, la cual cuenta con un instrumento (tecnología) llamado contabilidad, que surge de la aplicación de la metrología, la matemática y la economía principalmente, y que es capaz de generar su propio cuerpo de estudio.

En un contexto configurado por la anterior exhibición de ideas, puede indicarse que el rechazo a la práctica técnico instrumental de la contabilidad, agenciada por quienes impulsan la pretensión de cientificidad, debe ser asumido como un esfuerzo permanente por desnaturalizar a la contabilidad, quitarle su esencia como herramienta de conocimiento para la generación de información a la medida de los imaginarios sociales. En síntesis, las comunidades académicas agencian su desinstrumentalización al no reconocerla como una tecnología con cuerpo de estudio propio. Esto hace que se descuide el papel político que debe jugar el contador público. El esfuerzo por lograr un estatus científico de la contabilidad distrae el trabajo de quienes deberían darle el estatus científico a la profesión en sí. Esto no significa que la formación en la mera instrumentalización se justifique, sino que no hay que derrochar esfuerzos en estratificar un instrumento en ciencia, principalmente, si desde el enfoque hermenéutico, lo importante es comprender e interpretar el mundo para propender por hacerlo más confortable a los seres vivos.

La sociedad se encuentra en la demanda de la construcción de las lentes que permitirán a la contabilidad la interpretación de la información referente a la circulación de los recursos de índole inmaterial, como el conocimiento y de índole pública, como el medio ambiente, la pureza del agua y del aire, entre otros.

\section{Elementos para debates futuros}

Resulta permisible preguntarse por la importancia del impacto de la contabilidad en la sociedad. Por la relación y consistencia e, incluso, la existencia de ciencias como la economía sin información contable. La eficiencia de la administración sin información pertinente de la circulación de recursos de la organización y 
sin una interpretación surgida de los datos generados por la contabilidad. Estas cuestiones pueden vislumbrar una importancia superior de la contabilidad como generadora de insumos para el desarrollo de la economía y la administración e incluso la política, fundamentado en su aspecto sociológico.

En virtud de la posibilidad de modificación de las condiciones sociales vigentes, que son el resultado de validaciones sociales y no situaciones dadas, se hace necesario cuestionarse sobre cuáles son los aspectos de la sociedad que reciben influencia directa de la información contable en ese proceso de construcción de los imaginarios y las verdades compartidas. Interpretar cómo estos aspectos influyen en la calidad de vida de las personas y definir cómo los contadores públicos pueden participar en la construcción de una sociedad más confortable para todos. Propender por definir si es posible la existencia de una contabilidad neutral de la cual luego se deslinden informes que tomen la forma exigida por cada actor o si, por el contrario, esta desde su concepción lleve impregnada la naturaleza de quien exige de ella información.

Finalmente, debe profundizarse conceptualmente en el aterrizaje de la metrología en los aspectos contables, de tal forma que se logre la consolidación y fortalecimiento de vasos conductores entre ambos aspectos, para convertir en un reto los esfuerzos por realizar análisis interdisciplinarios desde las disciplinas contables.

\section{Agradecimientos}

El presente artículo surge de la reflexión realizada sobre los resultados y la construcción del marco teórico de la investigación denominada Modelo de contabilidad en la estructura social de Barranquilla (P3-003-INT), que, en su etapa inicial busca construir un concepto de contabilidad. Este trabajo se realizó en la Corporación Universitaria Empresarial de Salamanca, CUES, Barranquilla. La etapa inicial de este trabajo finalizó en diciembre de 2015.

\section{Referencias}

Anderson, B. (1993). Comunidades imaginadas. Reflexiones sobre el origen y la difusión del nacionalismo. Ciudad de México: Fondo de Cultura Económica, FCE.

Araujo-Ensuncho, J. A. (2007). Los recursos: objeto de estudio de la contabilidad. Contaduría Universidad de Antioquia, 50, 177-186. Recuperado de https://aprendeenlinea.udea.edu.co/revistas/index.php/cont/article/v iew/2127/1737

Arendt, Hannah (1994). La condición humana. Buenos Aires: Paidós.

Arendt, Hannah (1995). De la historia a la acción. Barcelona: Novagrafik, S. L.

Arendt, Hannah (2003). La condición humana. Buenos Aires: Paidós.

Augé, M. (1996). El sentido de los otros. Actualidad de la antropología. Buenos Aires: Editorial Paidós, SAICF.

Bachelard, Gaston (1973). El compromiso racionalista. Buenos Aires: Siglo XXI.

Baeza-Rodríguez, M. A. (2011). Elementos básicos de una teoría fenomenológica de los imaginarios sociales. Barcelona: Tusquets Editores.

Baker, C. Richard (2009). ¿Cual es el significado del \#interés público\#? Examinando la ideología de la profesión de la contaduría pública americana. En Mauricio Gómez-Villegas \& Carlos Mario Ospina-Zapata, Avances interdisciplinarios para una comprensión crítica de la contabilidad. Textos paradigmáticos de las corrientes beterodoxas, 223-243. Medellín: Escuela de Administración y Contaduría Pública - Universidad Nacional de Colombia y Departamento de Ciencias Contables - Universidad de Antioquia.

Bauman, Zygmunt (2002). La hermeneútica y las ciencias sociales. Buenos Aires: Nueva Visión SAIC.

Beriain, J. (2011). El imaginario social moderno: una postmetafísica de la indeterminación y la contingencia. En Juan R. Coca, Jesús A. Valero-Matas, Francesca Randazzo \& Juan Luis Pintos, coords. Nuevas posibilidades de los imaginarios sociales, 113-139. La Codosera, Badajoz, España: Asociación Cultural Tremn y el Centro de Estudios 
y Análisis Social de Galicia, TREMN-CEASGA. Recuperado de http://libros.metabiblioteca.org:8080/bitstre am/001/449/1/Nuevas\%20posibilidades\%20de\%20los\%20imaginarios\%20sociales.pdf

Betancur, H. D. (2012). La contabilidad: un incesante caminar por lo epistemológico y lo ontológico, nuevas perspectivas investigativas. Lúmina, 13, 106-126. Recuperado de http://revistasum.umanizales.edu.co/ojs/inde x.php/Lumina/article/download/681/803

Bourdieu, P., Chamboredon, J. C. \& Passeron, J. C. (2002). El oficio de sociólogo: presupuestos epistemológicos. Buenos Aires: Siglo XXI Editores Argentina.

Bunge, M. (1960). La ciencia, su método y su filosofía. Buenos Aires: Fundación Promotora Colombiana de la Cultura. Recuperado de https://drive.google.com/file/d/0B5tVYXnH1yduNGVjMTVmZjMtMWE5ZC00 MDk3LWE4MWUtNDc3YTI1MmM1OWEw/view?ddrp=1\&hl=es\#

Carretero-Pasin, E. (2011). Imaginario e identidades sociales: los escenarios de actuación del \#Imaginario social\# como configurador de vínculo comunitario. En Juan R. Coca, Jesús A. Valero-Matas, Francesca Randazzo \& Juan Luis Pintos, coords. Nuevas posibilidades de los imaginarios sociales, 99-112. La Codosera, Badajoz, España: Asociación Cultural Tremn y el Centro de Estudios y Análisis Social de Galicia, TREMN-CEASGA. Recuperado de http://libros.metabiblioteca.org:8080/bitstream/001/449/1/Nuevas\%20posibilidades\%20de \%20los\%20imaginarios\%20sociales.pdf

Castoriadis, C. (1975). La institución imaginaria de la sociedad. Barcelona: Tusquets Editores.

Certeau, M. (2000). La invención de lo cotidiano, 1 Artes de hacer. México: Instituto Tecnológico y de Estudios Superiores de Occidente, ITESO. Recuperado de https://www.minipimer.tv/txt/30sept/De\%20Certeau\%20 Michel\%20La\%20Invencion\%20de\%20Lo\%20Cotidiano\%201\%20Artes\%20de\%20Hacer.pdf

Chatfield, M. (1977). Contemporary Studies in the Evolution of Accounting Thought. Belmont, California: Dickenson.

Cooper, D. (1980). Discussion of \#Towards a Political Economy of Accounting\#. Accounting, Organization and Society, 5(1), 161-166.

Cuevas, J. J. (2008). La empresa como demiurgo de la educación del profesional de la contaduría pública. En Libro de ponencias del XX Congreso Nacional de Estudiantes de Contaduría Pública, 25-47. Santiago de Cali: Dirección Postal Editores.

Dubet, F. (2012).¿Para quésirve realmente un sociológo? Buenos Aires: Siglo XXI Editores.

Echeverría, J. (1999). Introducción a la metodología de la ciencia: la filosofía de la ciencia en el siglo XX. Madrid: Gráficas Rógar S.A.

Gómez-Villegas, M. (2005). Breve introducción al estado del arte de la orientación crítica en la disciplina contable. Porik An, 10, 13-37. Recuperado de http://www.unicauca.edu.co/porik_an/imagenes_3noanteriores/No.10p orikan/porikan_1.pdf

Gómez-Villegas, M. (2011). Pensando los fundamentos de la contabilidad como disciplina académica. Lúmina, 12, 120-150. Recuperado de http://revistasum.umanizales.edu.co/ojs/index.php/Lumina/article/view/696/819

Gómez-Villegas, M. \& Ospina-Zapata, C. M. (2009). Ampliando las fronteras en la disciplina contable: una introducción para la contextualización de los ejemplares heterodoxos. En Mauricio Gómez-Villegas \& Carlos Mario Ospina-Zapata, Avances interdisciplinarios para una comprensión critica de la contabilidad. Textos paradigmáticos de las corrientes heterodoxas, 13-35. Medellín: Escuela de Administración y Contaduría Pública Universidad Nacional de Colombia y Departamento de Ciencias Contables - Universidad de Antioquia.

Gracia-López, É. (2006). Sobre las prácticas de gestión en la universidad. Lúmina, 07, 110-128. Recuperado de http:/ /revistasum.umanizales.edu.co/ojs/index.php/Lumina/article/viewFile/1179/1255

Guiliani, D. (29 de septiembre de 2015). Los imaginarios profesionales del trabajo social. Recuperado de http://www. catedras.fsoc.uba.ar/ferraros/BD/dg\%20improfts.pdf

Jaffe, K. (05 de abril de 2012). ¿Qué es la ciencia? Una visión evolutiva. Recuperado de Doctorado Interdisciplinario Ciencias http://www.dic.coord.usb.ve/Que\%20es\%20la\%20ciencia.pdf

Kaplan, R. S. (1984). The Evolution of Management Accounting. Accounting Review, 390-418.

Kédrov, M. B. \& Spirkin, A. (1968). La ciencia. Ciudad de México: Grijalbo. 
Kuhn, T. S. (1992). La estructura de las revoluciones cientificas. 2a reimpresión. Chicago: Fondo de la Cultura Económica, FCE. Santa Fe de Bogotá.

Larrea y Dávalos, E. (1997). La homologación internacional de la normatividad contable. Necesidad y expresión concreta en un contexto de internacionalización y regionalización económica. Revista de Contaduría y Administración, 47-66. Recuperado de http://www.ejournal.unam.mx/rca/184/RCA18405.pdf, http://www. cya.unam.mx/index.php/cya/article/download/264/663

Lather, P. (1992). Critical Frames in Educational Research: Feminist and Post-Structural Perspectives. Theory into Practice, 31 (2), 87-99.

Laya, A. (2011). Los principios y postulados básicos de la contabilidad: una perspectiva histórica-conceptual desde la doctrina contable. Actualidad Contable FACES, 14(23), 79-101. Recuperado de http://www.redalyc.org/html /257/25720652006/

Lee, T. A. \& Parker, R. H. (1979). The Evolution of Corporate Financial Reporting. London: Nelson.

Littleton, A. C. \& Zimmerman, V. K. (1962). Accounting Theory: Continuity and Change. Englewood Clifs, New Jersey: Prentice Hall.

López-Santiso, H. (2001). Contabilidad, administración y economía, su relación epistemológica. Buenos Aires: Ediciones Macchi.

Machado, M. A. (2009). Contabilidad y realidad: una relación crítica bajo el enfoque de la representación. Actualidad Contable FACES, 12(19), 38-55. Recuperado de http://www.redalyc.org/pdf/257/25715409005.pdf

Martínez-Pino, G. L. (2007). Los paradigmas contables: la borrosa impronta de una interpretación epistemológica. Lúmina, 08, 205-234. Recuperado de http://revistasum.umanizales.edu.co/ojs/index.php/Lumina/article/vie wFile/1191/1267

Mejía-Soto, E., Montes-Salazar, C. A. \& Mora-Roa, G. (2013). Identificación del objeto de estudio de la contabilidad. Libre Empresa, 19, 51-70. Recuperado de http://revistasojs.unilibrecali.edu.co/index.php/libre-empresa, https: //www.academia.edu/28741421/Identificaci\%C3\%B3n_del_objeto_de_estudio_de_la_contabilidad.pdf

Mejía-Soto, E., Mora-Roa, G., \& Montes-Salazar, C. A. (2013). Adscripción de la contabilidad a la estructura general del conocimiento. Cuadernos de Contabilidad, 14(34), 159-187. Recuperado de http://revistas.javeriana.edu.co /index.php/cuacont/article/download/6072/4892

Méndez-Picazo, M. T. \& Ribeiro-Soriano, D. (2012). Aspectos históricos del pensamiento contable: de los inicios al paradigma de la utilidad. Nuevas Corrientes de Pensamiento Económico, 865, 71-78. Recuperado de http://www .revistasice.com/CachePDF/ICE_865_71-78_9FD9BB881BB93625A97001DC4EBB852E.pdf

Miller, P. \& O'Leary, T. (2009). La contabilidad y la construcción de la persona gobernable. En Mauricio Gómez-Villegas \& Carlos Mario Ospina-Zapata, Avances interdisciplinarios para una comprensión crítica de la contabilidad. Textos paradigmáticos de las corrientes heterodoxas, 127-169. Medellín: Escuela de Administración y Contaduría Pública - Universidad Nacional de Colombia y Departamento de Ciencias Contables - Universidad de Antioquia.

Mora-Nawrath, H. (27 de abril de 2017). La medición en Ciencias Sociales: representación empirica de conceptos abstractos. Recuperado de ProEva, Uruguay http://eva.fcs.edu.uy/pluginfile.php/8362/mod_folder/content/... /h_mora_medirccss.pdf?

Nietzsche, F. (1970). Sobre verdad y mentira en sentido extramoral. Buenos Aires: Ediciones Prestigio.

Ospina-Zapata, C. M., Gómez-Villegas, M. \& Rojas-Rojas, W. (2014). La constitución de la subjetividad en la educación contable: del proceso implícito a la visibilización de sus impactos. Cuadernos de Contabilidad, 15(37), 187-211. Recuperado de http://revistas.javeriana.edu.co/index.php/cuacont/article/viewFile/9007/7300

Quijano-Valencia, O., Gracia-López, E., Martínez-Pino, G. L., Ariza-Buenaventura, E. D., \& Rojas-Rojas, W. (2002). Del hacer al saber. Realidadesy perspectivas de la educación contable en Colombia. Popayán: Universidad del Cauca, Centro Colombiano de Investigación Contable, CCINCO.

Randazzo, F. (2011). La irremediable intromisión de lo imaginario. En Juan R. Coca, Jesús A. Valero-Matas, Francesca Randazzo \& Juan Luis Pintos, Coords. Nuevas posibilidades de los imaginarios sociales, 9-14. La Codosera, Badajoz, España: Asociación Cultural Tremn y el Centro de Estudios y Análisis Social de Galicia, TREMN- 
CEASGA. Recuperado de http://libros.metabiblioteca.org:8080/bitstream/001/449/1/Nuevas\%20posibilida des\%20de\%20los\%20imaginarios\%20sociales.pdf

Roberts, J. \& Scapens, R. (2009). Sistemas contables y sistemas de rendición de cuentas: comprendiendo las prácticas contables en sus contextos organizacionales. En Mauricio Gómez-Villegas \& Carlos Mario Ospina-Zapata, Avances interdisciplinarios para una comprensión critica de la contabilidad. Textos paradigmáticos de las corrientes heterodoxas, 103-121. Medellín: Escuela de Administración y Contaduría Pública - Universidad Nacional de Colombia y Departamento de Ciencias Contables - Universidad de Antioquia.

Rueda-Delgado, Gabriel (2010). El papel de la contabilidad ante la actual realidad económica, social y política del país. Más allá de la convergencia de prácticas mundiales. Cuadernos de Contabilidad, 11(28), 149-169. Recuperado de http://revistas.javeriana.edu.co/index.php/cuacont/article/view/3202/2434

Rueda-Delgado, G. (2012). Los aportes de la teoría de la acción comunicativa y sus conceptos a una contabilidad para el entendimiento y la integración de la sociedad. Universitas Humanistica, 74, 227-263. Recuperado de http://r evistas.javeriana.edu.co/index.php/univhumanistica/article/view/3649/3189

Sabino, C. (1992). El proceso de investigación. Caracas: Panapo.

Sánchez-Capdequí, C. (2011). Dialéctica de lo social. El imaginario del iniciar y el iniciar de lo imaginario. En Juan R. Coca, Jesús A. Valero-Matas, Francesca Randazzo \& Juan Luis Pintos, coords. Nuevas posibilidades de los imaginarios sociales, 15-30. La Codosera, Badajoz, España: Asociación Cultural Tremn y el Centro de Estudios y Análisis Social de Galicia, TREMN-CEASGA. Recuperado de http://libros.metabiblioteca.org:8080/bitstre am/001/449/1/Nuevas\%20posibilidades\%20de\%20los\%20imaginarios\%20sociales.pdf

Sarlo, B. \& Altamirano, C. (2002). Términos críticos de sociología de la cultura. Buenos Aires: Editorial Paidós SAICF.

Sarmiento-Ramírez, H. J. (2007). Retorno a la idea. Elementos metodológicos para la construcción de conceptos propedéuticos de investigación contable. Lúmina, 8, 43-57. Recuperado de http://revistasum.umanizales.edu.c o/ojs/index.php/Lumina/article/viewFile/1184/1260

Seoane-C., J. B. (2006). La disputa del canon clásico en la sociología. Espacio Abierto, 15(4), 705-724. Recuperado de http://www.redalyc.org/pdf/122/12215401.pdf

Taton, R. (1973). Causalidad y accidentalidad de los descubrimientos cientificos. París: Editorial Labor.

Tua-Pereda, J. (1988). Evolución del concepto de Contabilidad a través de sus definiciones. En M. d. España, XXV Años de Contabilidad Universitaria en España, homenaje al Dr. D. Mario Pifarré-Riera, 895-956. Madrid: Instituto de Planificación Contable.

Vargas-Guillén, G. (2006). Tratado de epistemología. fenomenología de la ciencia, la tecnología y la investigación social. Bogotá: San Pablo.

Wirth, M. C. (1999). Acerca de la ubicación de la contabilidad en el campo del conocimiento. Tesis doctoral, Facultad de Ciencias Económicas, Universidad de Buenos Aires, UBA, Buenos Aires. Disponible en: http://bibliotecadigit al.econ.uba.ar/download/tesis/1501-1156_WirthMC.pdf

Ynoub, R. (2015). Cuestión de método, aportes para una metodología crítica. Ciudad de México: Cengage Learning Editores.

\section{Notas}

1325 estudiantes de séptimo semestre de Contaduría Pública del período 2013-2 a 2015-2 en una universidad privada en la ciudad de Barranquilla, Colombia.

2 Se revisaron planes de estudio de 30 instituciones de educación superior de Colombia, pertenecientes a la Asociación Latinoamericana de Facultades de Contaduría y Administración, ALAFEC, en 2015 y 15 no agremiadas a ALAFEC.

* $\quad$ Artículo de reflexión.

Licencia Creative Commons CC BY 4.0

Para citar este articulo: Velandia-Pacheco, G. J., Anguila-Carrillo, A. R. \& Archibold-Barrios, W. G. (2017). La contabilidad como tecnología blanda: una visión desde los imaginarios sociales. Cuadernos de Contabilidad, 17(45), 1-21. https://doi.org/10.11144/Javeriana.cc18-45.ctvi 